\title{
Chylopericardium with cardiac tamponade secondary to acute Epstein-Barr virus peri-myocarditis
}

\author{
D. A. A. M. Schellings • M. F. Boomsma • M. J. H. M. Wolfhagen • \\ M. Hijmering • A. R. Ramdat Misier
}

Published online: 21 November 2013

(C) The Author(s) 2013. This article is published with open access at Springerlink.com

Case

A 20-year-old man, with no medical history, was referred to the emergency ward because of severe shortness of breath. Heteroanamnesis revealed that he had suffered influenza-like symptoms for a week, which had become worse in the last 24 h. Physical examination showed a critically ill patient with high fever (body temperature $40^{\circ} \mathrm{C}$ ), tachycardia (pulse rate $110 / \mathrm{min}$ ), tachypnoea (respiratory rate $35 / \mathrm{min}$ ), hypotension (RR 100/60 mmHg), and elevated jugular venous pressure; on auscultation diffuse pulmonary crackles were heard. In addition there was a low peripheral oxygen saturation (85\%). Electrocardiography showed sinus tachycardia, with a low voltage of the QRS complex in the limb leads, but was otherwise normal.

D. A. A. M. Schellings • M. F. Boomsma • M. J. H. M. Wolfhagen • M. Hijmering • A. R. Ramdat Misier

Isala Clinics, Thorax Centre, Zwolle, the Netherlands

D. A. A. M. Schellings $\cdot$ A. R. Ramdat Misier $(\square)$

Department of Cardiology, Isala Clinics, Dr. Van Heesweg 2, 8025

AB Zwolle, the Netherlands

e-mail: A.RamdatMisier@diagram-zwolle.nl

M. F. Boomsma

Department of Radiology, Isala Clinics, Zwolle, the Netherlands

M. J. H. M. Wolfhagen

Department of Clinical Microbiology, Isala Clinics, Zwolle, the Netherlands

\section{Hijmering}

Department of Intensive Care, Isala Clinics, Zwolle, the Netherlands

Present Address:

D. A. A. M. Schellings

Department of Cardiology, Slingeland Hospital, Doetinchem, the Netherlands
Meanwhile, the patient's condition deteriorated which made a transfer to the intensive care unit (ICU) necessary with subsequent invasive mechanical ventilation and treatment with inotropic agents. Also broad-spectrum antibiotics were given, because severe pneumonia was suspected. The main laboratory blood tests revealed a white blood cell count $(50 \times$ $10 \%$ ), CRP (489 mmol/l) and liver enzymes (aspartate aminotransferase/alanine aminotransferase 47/61 U/1, gamma-glutamyl transpeptidase $219 \mathrm{U} / 1$, and alkaline phosphatase $159 \mathrm{U} / \mathrm{l}$ ) with a disturbed renal function (creatinine $139 \mu \mathrm{mol} / \mathrm{l}$, glomerular filtration rate MDRD: $57 \mathrm{ml} / \mathrm{min} / 1.73 \mathrm{~m}^{2}$, and urea $10.4 \mathrm{mmol} / \mathrm{l}$ ). At chest X-ray the right lung base showed an air bronchogram with increased attenuation in the right lung base consistent with consolidation. In addition, diffuse bronchial interstitial oedema and cardiac enlargement were present (Fig. 1).

Because of these findings, transthoracic echocardiography was performed, showing severe impairment of left ventricular function and pericardial effusion with signs of cardiac tamponade (Fig. 2). Therefore, the patient underwent pericardiocentesis and $800 \mathrm{cc}$ of non-viscous milky fluid was evacuated, immediately leading to haemodynamic improvement. This fluid, which was initially regarded as purulent fluid, turned out to be chyle, because analysis revealed a high concentration of triglycerides and a cholesterol-triglyceride ratio $<1$. Bacterial analysis of both blood and pericardial fluid (chyle) by culture and broad range polymerase chain reaction analysis (PCR) on various viral pathogens was negative, except for the PCR on Epstein-Barr virus (EBV), which was positive with a higher viral load in the pericardial chyle than in the peripheral blood. Serological analysis suggested a previous EBV infection or a reactivation of the virus, which had caused perimyocarditis, because viral capsid antigen (VCA) IgG and Epstein-Barr nuclear antigen (EBNA) IgG were positive, but VCA IgM remained negative. 


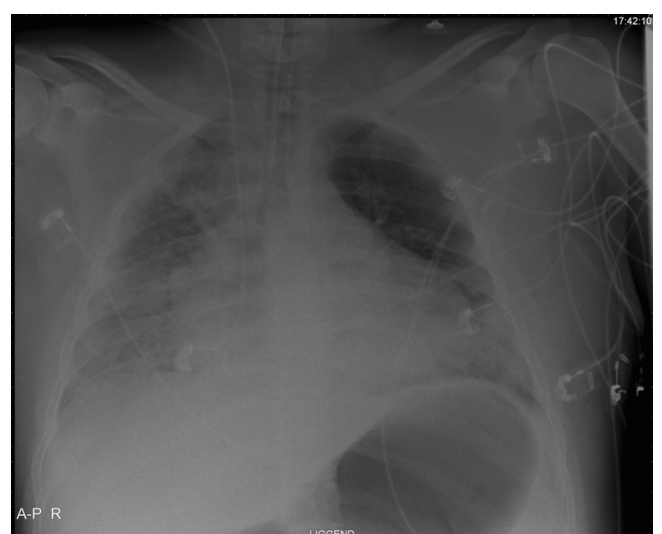

Fig. 1 AP, supine chest $X$-ray shows, next to a tracheal tube and a jugular catheter on the right, evident cardiac enlargement. The right lung base shows an air bronchogram with increased attenuation of the right lung base consistent with consolidation. Diffuse bronchial interstitial oedema due to congestion is present

During the following days, the patient recovered slowly. He was placed on a low fat diet with medium chain triglycerides for several weeks. After 1 week he was able to undergo cardiac magnetic resonance imaging (MRI). T2 weighted short tau inversion recovery (STIR) image showed a significant amount of pericardial fluid together with increased signal intensity of the pericardium due to oedema in the pericardium with also late gadolinium enhancement (Fig. 3a, b). Left ventricular function was improved. After 3 weeks, the patient was recovering and could be discharged from hospital, 1 month after admission.

\section{Discussion}

Acute myocarditis due to EBV is a rare entity with an estimated prevalence of $1 \%$ among patients with acute viral myocarditis $[1,2]$. Serological evidence for EBV infection does not prove the diagnosis, when IgM antibodies remain

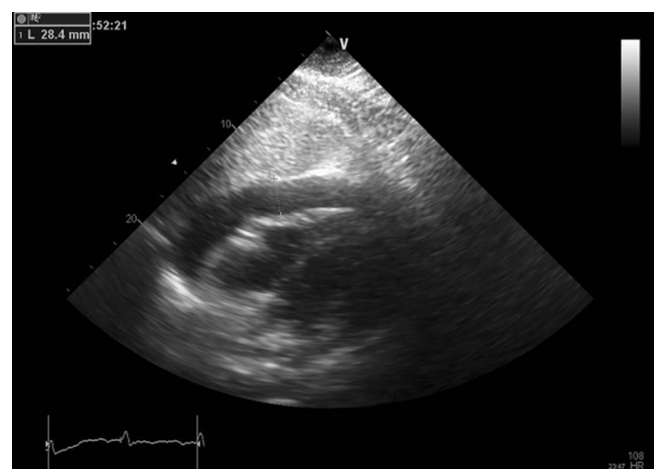

Fig. 2 Transthoracic echocardiography (subcostal view) showing almost $3 \mathrm{~cm}$ pericardial Fluid (dotted line)
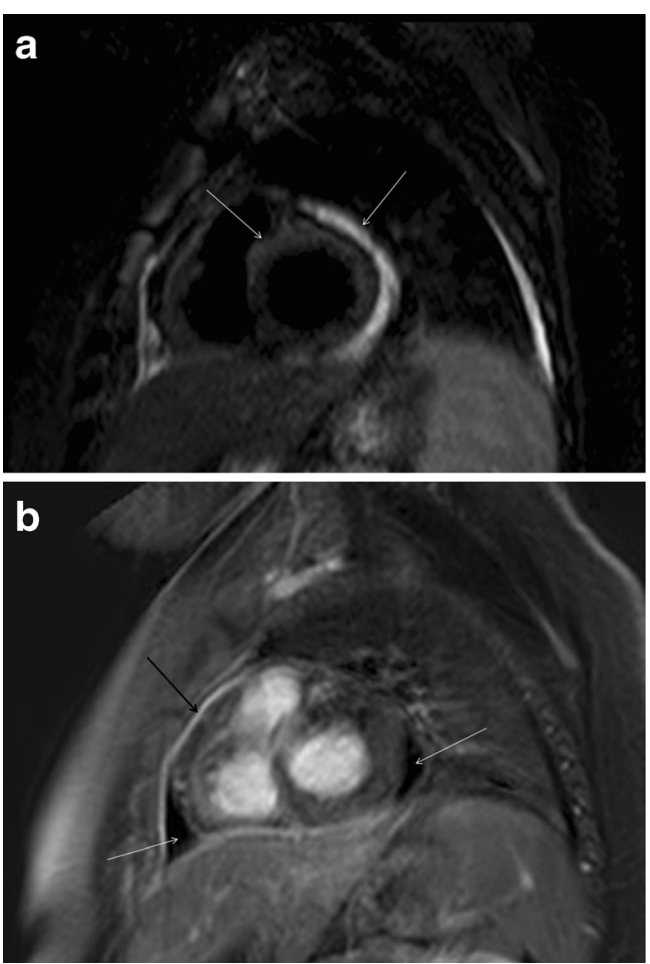

Fig. 3 MRI scans of the patient's heart obtained across the long axis. a T2 weighted 'short tau inversion recovery' STIR image showing a significant amount of pericardial fluid together with increased signal intensity of the pericardium (right arrow) as well as the myocardium (left arrow) due to oedema b 'Late enhancement' image obtained 15 min following administration of intravenous gadolineum showing enhancement of the pericardium (black arrow) consistent with inflammation. This image also shows pericardial effusion (white arrows)

negative, despite positive $\mathrm{IgG}$, as happened in this case. Therefore, diagnosis is often based on exclusion of other aetiologies [2]. However, in this case, as we have shown, presence of pericardial fluid and subsequent analysis played a key role in diagnosis assessment. The occurrence of chylopericardium in general is uncommon and, to our best knowledge, has not been reported before in relation to acute EBV peri-myocarditis. Chyle entering the pericardial cavity, without the existence of chylothorax, in non-traumatic infectious patients, has been reported before in one patient with pneumonia and one patient with tuberculosis $[3,4]$. Its mechanism is unclear and it has been suggested that inflammatory injury of pre-existing anomalous lymphatic vessels may play a role, leading to communication between the thoracic duct and the pericardial space [4]. Treatment of chylopericardium can be difficult and is controversial but beneficial effects of a medium chain triglycerides diet have been reported [4] as well as surgical ligation at the place of the leaking thoracic duct [5]. When peri-myocarditis is suspected, cardiac MRI is the imaging modality of choice because of its excellent assessment of ventricular function and cardiac oedema [6]. 


\section{Conclusion}

Acute EBV peri-myocarditis accompanied by tamponade due to chylopericardium is a very rare condition which, to our best knowledge, has not been reported before. Assessment of the diagnosis may be difficult, however - when present — pericardial fluid may contain the key to diagnosis. Furthermore, performance of cardiac MRI is mandatory.

\section{Funding None}

\section{Conflict of interest None declared}

Open Access This article is distributed under the terms of the Creative Commons Attribution License which permits any use, distribution, and reproduction in any medium, provided the original author(s) and the source are credited.

\section{References}

1. Roubille F, Gahide G, Moore-Morris T, et al. Epstein Barr virus (EBV) and acute myopericarditis in an immunocompetent patient: first demonstrated case and discussion. Intern Med. 2008;47:627-9.

2. Zabala Lopez S, Vicario JM, Lerin FJ, et al. Epstein-Barr virus myocarditis as the first symptom of infectious mononucleosis. Intern Med. 2010;49:569-71.

3. Dib C, Tajik AJ, Park S, et al. Chylopericardium in adults: a literature review over the past decade (1996-2006). J Thorac Cardiovasc Surg. 2008;136:650-6.

4. Kentsch M, Doring V, Rodemerk U, et al. Primary chylopericardiumstepwise diagnosis and therapy of a differential diagnostically important illness. Z Kardiol. 1997;86:417-22.

5. Mehrotra S, Peeran NA, Bandyopadhyay A. Ideopathic chylopericardium. An unusual cause of cardiac tamponade. Tex Heart Inst J. 2006;33:249-52.

6. Bang DW, Kim TH, Noh HJ, et al. Epstein-Barr virus induced acute myocarditis diagnosed using cardiac magnetic resonance imaging. Int J Cardiol. 2009;134:e32-4. 